УДК 330.1

DOI: 10.14451/1.178.44

\title{
ОЦЕНКА ЭФФЕКТИВНОСТИ КАДРОВЫХ МЕРОПРИЯТИЙ НА ОСНОВЕ ОЦЕНКИ ПРИРАЩЕНИЯ ЧЕЛОВЕЧЕСКОГО КАПИТАЛА ОРГАНИЗАЦИИ
}

\author{
(C) 2019 Александров Игорь Николаевич \\ кандидат экономических наук, доцент \\ Санкт-Петербургский политехнический университет Петра Великого, Россия, Санкт-Петербург \\ E-mail:a7830298@gmail.com \\ (C) 2019 Рассказова Ольга Анатольевна \\ кандидат экономических наук, доцент \\ Санкт-Петербургский политехнический университет Петра Великого, Россия, Санкт-Петербург \\ E-mail: olanka777@yandex.ru \\ (c) 2019 Бурмистров Андрей Николаевич \\ кандидат экономических наук, доцент \\ Санкт-Петербургский политехнический университет Петра Великого, Россия, Санкт-Петербург \\ E-mail: isar@mail.ru \\ (c) 2019 Синявина Мария Павловна \\ старший преподаватель \\ Санкт-Петербургский политехнический университет Петра Великого, Россия, Санкт-Петербург \\ E-mail:sinmp@inbox.ru
}

Статья направлена на повышение эффективности оценки кадровых мероприятий. В работе выявляются проблемы анализа экономической и социальной эффективности реализуемых в компании проектов. Предложен метод оценки изменения человеческого капитала организации на основе оценки приращения общего потенциала компании в результате кадровых мероприятий. Использование предлагаемого метода позволяет оценивать интеллектуальный капитал для широкого круга компаний.

Ключевые слова: кадровые мероприятия, социальная эффективность, потенциал компании, интеллектуальный капитал, человеческий капитал, структурный капитал, клиентский капитал, стратегическое управление.

Актуальность данного исследования обусловлена тем, что в настоящее время в большинстве отраслей экономики именно соответствие уровня компетенций персонала решаемым задачам определяют долгосрочную конкурентоспособность организации.

Недостаточная производительность труда является одной из системных проблем современных российских компаний. Стоимость человеческого капитала, как составляющей интеллектуального капитала в современных коммерческих организациях, может многократно превышать стоимость ее иных активов, что делает качественное управление данным ресурсом важейшей задачей. Человеческий капитал включает уникальные навыки и компетенции сотрудников, определяя, в значительной мере, конкурентоспособность компании в целом.

Стратегическое управление персоналом на- правленно на достижение соответствия уровня компетенций сотрудников задачам организации и призвано повысить конкурентоспособность компании и способствовать выполнению ее миссии.

Для объективной оценки усилий менеджмента по развитию и сбережению человеческих ресурсов требуются соответствующие методики, которые не всегда совершенны.

Для российских компаний имеющих традиционно невысокую производительность труда особенно важным становится возможность оценки эффективности инвестиций в кадровые мероприятия направленные на развитие человеческого капитала.

В настоящее время, с помощью общеизвестных методов инвестиционного анализа, менеджеры могут достаточно объективно оценить эффективность вложения капитала в модерни- 
зацию или обновления производственных активов. Сопоставляя доходы и затраты на мероприятия можно, с высокой долей вероятности, сделать вывод о целесообразности тех или иных инвестиционных вложении. Инвестиции в персонал или человеческий капитал не поддаются классической оценке.

Мероприятия, направленные на развития человеческого капитала компании должны соответствовать общей стратегии организации. При этом необходимо учитывать, что долгосрочное успешное функционирование коммерческой организации предполагает, что все заинтересованные в ее деятельности группы лиц (это не только собственники и сотрудники, но и потребители, контрагенты, общество) будут получать пользу в результате ее деятельности. При том, что изначально интересы данных групп различны, стратегия компании может позволить соблюсти некий приемлемый для всех баланс (иначе компания уйдет с рынка).

В основном при оценке эффективности кадровых мероприятий практикуются два основных подхода [4]. Исходя из первого подхода, главным показателем эффективности кадровых мероприятий является экономическая выгода. Социальный эффект считается второстепенным.

Второй подход предполагает, что проекты кадровых мероприятий должны, в первую очередь, ориентироваться на выполнение социальных результатов. Экономическая оценка уже выбранных социально эффективных проектов, в дальнейшем позволяет выбрать из них самый приемлемый.

Оба подхода могут применяться, учитывая специфику той или иной организации. Экономический эффект от кадровых мероприятий может возникнуть как в сфере производства, так и в сфере управления. Снижение нагрузки на менеджеров в результате перераспределения обязанностей, избавление от несвойственных избыточных функций, рост производительности за счет совершенствования процесса обмена и получения информации может дать значимый эффект для компании.

В сфере производства кадровые мероприятия могут быть направлены на снижение потерь, повышения производительности, поиск путей более эффективного использования запасов и т.П.

Наиболее эффективные кадровые мероприятия направлены сразу на решение нескольких задач, причем они часто реализуются одновременно с совершенствованием других систем организации.

Последствиями непродуманной кадровой политики могут приводить к таким отрицательным последствиям, как формирование напряженной психологической атмосферы в организации. В свою очередь это может приводить к росту конфликтных ситуаций как между руководителями и подчиненными, так и между коллегами.

Любые конфликты в компании чреваты снижением производительности труда. Так же, к снижению отдачи от персонала будет приводить уменьшение инициативы, вызванное неопределенностью и общее снижение лояльности сотрудников. Худущим результатом развития конфликтов в организации может быть уход наиболее востребованных на рынке работников.

Пути снижение вышеописанных рисков и преодоления сопротивления персонала лежат в честном и открытом информировании о проходящих изменениях и вовлечении сотрудников в процесс принятия решений.

Учитывая вышеизложенное, очевидно, что параллельно с достижением экономического эффекта от мероприятий, менеджмент должен обеспечить некоторую социальную эффективность

Социальная эффективность кадровых мероприятий призвана обеспечить комфортную среду для сотрудников организации.

Так же значимым для сотрудников является обеспечение возможности развития и реализации их потенциала, в том числе с помощью обучения. Когда мы говорим комфортном социально-психологическом климате, мы предполагаем не только достойные условия труда, но низкий уровень конфликтов внутри коллектива, возможности для обмена важной информацией. Так же важно, чтобы компания обеспечивала сотрудников некоторой степенью свободы в возможности принимать решения, определять методику выполнения работы и ее интенсивность и пр.

В современных высокотехнологичных компаниях процесс обмена знаниями становится ключевым для эффективности всей организации. Несмотря на то, что технически данный процесс становится все более совершенным, именно без налаженных связей внутри коллектива информационных обмен не будет макси- 
мально эффективным.

Все вышеперечисленные социальные улучшения, должны реализовываться в компании комплексно [5]. Очевидно, что ресурсы организации всегда ограниченны и необходимо соблюдать некий баланс в процессе планирования их расходования на вышеперечисленные мероприятия.

Для разных сотрудников (исходя из их ментальных или культурных особенностей, уровня образования, сферы деятельности), ценность тех или иных социальных благ может существенно отличаться.

Социальная эффективность мероприятий предполагает снижение отрицательных с точки зрения персоналии и менеджмента изменений в организации. К ним можно отнести:

- ущерб, наносимый здоровью сотрудников неблагоприятными условиями работы в компании;

- ущерб, который наносится личности сотрудников в результате работы, например перегрузки и стрессовые ситуации.

Очевидно, что между экономической и социальной эффективностью кадровых мероприятий существует прямая взаимосвязь.

Социальную эффективность мероприятий можно обеспечить только при экономической устойчивости предприятия.

Но так же важно, что высокая работоспособность и экономическая эффективность возможна только при эффективности социальной.

Поэтому социальные результаты должны быть включены в состав общих результатов компании при оценке ее эффективности.

Ниже приведен предлагаемый авторами подход к оценке эффективности кадровых мероприятий построенный на основе подхода к оценке общего потенциала [1].

Задачей является определение приращения человеческого капитала организации в результате запланированных кадровых мероприятий. Если приращение человеческого капитала будет положительным, то кадровые мероприятия будут признаны целесообразными.

Под потенциалом мы будем понимать меру возможностей компании, выраженную в деньгах. Ближе всего данная мера соотносится со стоимостью компании.

Оценка потенциала, как и оценка цены компании, строится на стоимости материальных активов, так и интеллектуального капитала.
Интеллектуальный капитал организации [3] это знания воплощенные в результатах интеллектуальной деятельности компании и знания ее сотрудников.

Человеческий капитал (ЧК) является составляющей общего Интеллектуального капитала организации (ИК). Наряду с Человеческим капиталом в Интеллектуальный капитал входят Рыночный капитал (PK) и Структурный капитал (CK) [3]. Иногда сложно или даже невозможно отнести некоторые активы только к одной составляющей интеллектуального капитала. Важно понимать, что конкурентные преимущества создаются в основном уникальным сочетанием составляющих интеллектуального капитала и материальных активов.

В настоящее время нет единой общепризнанной экспертным сообществом методики измерения Интеллектуального капитал организации.

Обычно Интеллектуальный капитал приблизительно оценивают путем вычитания стоимости чистых материальных активов организации из общей рыночной стоимости компании.

Для определения рыночной стоимости компании, чаще всего, нужна рыночная оценочная экспертиза, так как далеко не все организации свободно торгуются на бирже. Видится возможным предложить оценивать стоимость интеллектуального капитала как разницу между стоимостной оценкой потенциала организации и стоимостью ее чистых материальных активов. Так как потенциал является совокупным показателем всех ресурсов и возможностей организации, интеллектуальны капитал целиком может быть оценен по формуле:

$$
U^{k}=P^{k}-A_{m}^{k}
$$

Оценив потенциал, мы может определить значение интеллектуального капитала.

Для этого предлагается использовать один из подходов к оценке бизнеса (доходный).

Данных подход к оценке стоимости бизнеса предполагает учет возможных денежных потоков от его деятельности. Предлагается развитие данного подхода к оценке для определения потенциала $[1,2]$. Необходимо выделить некоторое количество самых перспективных инвестиционных проектов (ПИП) и рассчитать сумму чистых приведенных стоимостей (NPV) от них при анализе потенциала компании. Кроме NPV перспек- 
тивных инвестиционных проектов (ПИП) предлагается при оценке потенциала предприятия рассчитать постпрогнозную стоимость активов (ПСА) после окончания проектов:

$$
P^{k}=F^{k}+C^{k}
$$

где $P^{k}-$ потенциал $\mathrm{k} ; F^{k}-$ сумма чистых приведенных стоимостей перспективных инвестиционных проектов для компании $\mathrm{k} ; C^{k}-$ nостпрогнозная стоимость активов компании k на конец периода планирования.

Перспективные инвестиционные проекты это те проекты, которые предположительно будут иметь максимальный суммарный NPV. Выбор и прогнозирование данных проектов может осуществляться как силами менеджеров компании, так и внешними экспертами.

Перспективные инвестиционные проекты состоят из трех групп и включают:

1. Реализуемые проекты (p11,..., p1w);

2. Запланированы к реализации проекты (p21,..., p1q);

3. Потенциально возможные к реализации проекты (p31,..., p3g).

Таким образом, $F^{k}$ сумма чистых приведенных стоимостей предпочтительных инвестиционных проектов будет рассчитываться как:

$$
F^{k}=\sum_{i=1}^{w} N P V\left(p_{1 i}\right)+\sum_{j=1}^{q} N P V\left(p_{2 j}\right)+\sum_{t=1}^{g} N P V\left(p_{3 t}\right)(3)
$$

Авторы предполагают, что разделение общего денежного потока на отдельные потоки от реализуемых, запланированных к реализации и потенциально возможных проектов позволит индивидуально оценить риски каждого. Постпрогнозная стоимость активов $\left(C^{k}\right)$ рассчитывается на конец периода планирования.

Вышеперечисленные формулы могут позволить получить значение потенциала и ин- теллектуального капитала (как разницы между оценкой потенциала и чистыми материальными активами). Предложенный подход к оценке потенциала достаточно универсален.

Если рассчитать значения потенциала и интеллектуального капитала компании на момент оценки и вероятное значение данных показателей в случае реализации кадровых мероприятий, то в случае их положительного изменения, мероприятия могут считаться целесообразными.

Если принять в качестве допущения, что значения структурного и рыночного капитала, а также чистая стоимость материальных активов останутся неизменными в результате кадровых мероприятий, то приращение значения человеческого капитала от кадровых мероприятий будет совпадать с полученным значением приращения потенциала организации от данных мероприятий.

В качестве основных выводов необходимо отметить следующее:

Использование предложенного подхода не ограничивается только оценкой кадровых решений. Применение данного подхода для оценки потенциала и интеллектуального капитала может быть полезным дополнительным инструментом для оценки эффективности многих мероприятий направленных на организационные изменения. С помощью анализа приращения потенциала, подход дает возможность проводить оценку решений по предполагаемым слияниям, поглощениям или крупным инвестиционным проектам.

Предложенный подход может быть полезен не только менеджерам коммерческих структур. Он может использоваться представителями региональных или муниципальных органов власти с целью анализа и оценки проектов, направленных на стратегическое развитие территорий.

\section{Библиографический список}

1. Александров И.Н. Оценка интеллектуального капитала через призму экономического потенциала организации // Проблемы современной экономики, -№ 3-2016.

2. Александров И.Н. Федорова М.Ю. Оценка интеграционных сделок в туристической отрасли в интересах развития региональной экономики // Проблемы современной экономики, -№ 4-2018.

3. Козырев А.Н. Экономика интеллектуального капитала. Научные доклады -№ 7-2006. СПб.: НИИ менеджмента СПбГУ, 2006. С .30

4. Москвина, О.В. Оценка экономической и социальной эффективности мероприятий по совершенствованию системы управления персоналом / СибАГС.-Новосибирск: Изд-во СибАГС, 2011

5. Фещенко В.В. Когнитивный менеджмент и когнитивное моделирование: принципы, методы, функции// Экономика. Социология. Право. -№ 2-2018. 